\title{
Factors associated with prevalent and incident foot pain: data from the Tasmanian Older Adult Cohort Study
}

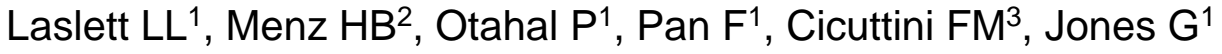 \\ ${ }^{1}$ Menzies Institute for Medical Research, University of Tasmania, Hobart, Australia \\ ${ }^{2}$ School of Allied Health, College of Science, Health and Engineering, La Trobe \\ University, Bundoora, Australia.
}

${ }^{3}$ Department of Epidemiology and Preventive Medicine, School of Public Health and Preventative Medicine, Monash University, Melbourne, Australia

Laura L Laslett BSc(Hons) MMedSci GDPH PhD, Senior Research Fellow

Laura.Laslett@utas.edu.au

Hylton B Menz BPod(Hons) PhD, H.Menz@latrobe.edu.au

Petr Otahal BSc, GDipSc Petr.Otahal@utas.edu.au

Feng Pan MBBS MMed PhD, Feng.Pan@utas.edu.au

Flavia Cicuttini MBBS(Hons) PhD MSc DLSHTM FRACP FAFPHM

flavia.cicuttini@monash.edu

Graeme Jones MBBS MMed MD FRACP FAFPHM, Professorial Research Fellow Graeme.Jones@utas.edu.au

Corresponding author:

Laura Laslett Laura.Laslett@utas.edu.au

Menzies Institute for Medical Research, University of Tasmania

Private Bag 23 HOBART TAS AUSTRALIA 7000

Phone: +61 362267736 , fax +61 362267704

Running head: Factors associated with prevalent and incident foot pain

Word count: 2950 words

\section{Funding}

The TASOAC study was supported by the National Health and Medical Research Council of Australia (Grant ID 302204); Arthritis Foundation of Australia; Tasmanian Community Fund; Masonic Centenary Medical Research Foundation, Royal Hobart Hospital Research Foundation and University of Tasmania institutional research grants scheme.

LLL is supported by a National Health and Medical Research Council Early Career Fellowship (Clinical Research Fellowship) (1070586). HBM is supported by a National Health and Medical Research Council Senior Research Fellowship (1135995). GJ is supported by a NHMRC practitioner fellowship (1023222).

\section{Page 1}

(C) 2018. This manuscript version is made available under the CC-BY-NC-ND 4.0 license http://creativecommons.org/licenses/by-nc-nd/4.0/ https://doi.org/10.1016/j.maturitas.2018.10.004 


\begin{abstract}
Objectives: To describe factors associated with prevalent and incident foot pain in a population-based cohort of older adults ( $n=1092)$.
\end{abstract}

Study Design: Longitudinal observational study.

Main Outcome Measures: Prevalent foot pain, incident foot pain after 5 years.

Methods: Potential correlates included demographic factors, anthropometry, leg strength, metabolic factors, steps per day (using pedometer), pain at 6 other sites, and psychological wellbeing. Data were analysed using log binomial models.

Results: Participants were aged $50-80$ years (mean 63 years), 49\% male, mean BMI 27.8 \pm 4.7 at baseline. Baseline prevalence of foot pain at baseline was $38 \%$ and incidence of new pain after 5 years was 20\%. Body mass index (BMI), pain at other sites (neck, hands, knees, pain at $\geq 3$ sites), and poorer psychological wellbeing were independently associated with baseline foot pain. Baseline BMI and pain in the neck, hands, and knees were independently associated with incident foot pain; but change in weight or BMI, total number of painful joints and psychological wellbeing were not. Self-reported diabetes and cigarette smoking were not associated with prevalent or incident foot pain.

Conclusions: This study demonstrates that heavier body mass and joint pain at multiple sites were consistently associated with prevalent foot pain and predict incident foot pain. Addressing excess body mass and taking a global approach to the treatment of pain may reduce prevalence and incidence of foot pain in older adults.

Key words: Foot; Obesity; Pain; Aged; Body Composition; Cohort Studies;

Pain/epidemiology/

Page 2

(C) 2018. This manuscript version is made available under the CC-BY-NC-ND 4.0 license http://creativecommons.org/licenses/by-nc-nd/4.0/ https://doi.org/10.1016/j.maturitas.2018.10.004 


\section{AUTHOR ACCEPTED MANUSCRIPT}

\section{Introduction}

Foot pain is common, with an estimated $24 \%$ of adults reporting foot pain on most days [1]. Foot pain is important, because it is an independent risk factor for locomotor disability [2], impaired balance, and increased risk of falling [3, 4], and functional activities of daily living $[5,6]$ among community-dwelling older adults. It also increases risk of developing knee symptoms and symptomatic radiographic knee OA in people with knee OA or at high risk of developing knee OA [7]. Therefore, identifying factors associated with existing and new foot pain is required in order to reduce pain in individuals and to address the burden of foot pain in the community .

Individuals with higher BMI are more likely to have foot pain [8], more likely to have existing foot pain persist, and to develop new foot problems $[9,10]$. Effect sizes are in the small to medium range, both cross-sectionally [8] and longitudinally $[9,10]$. The component of body mass most strongly associated with foot pain is fat mass, with evidence from both cross-sectional $[11,12]$ and longitudinal $[12,13]$ studies, and particularly fat in the android distribution (adipose tissue that accumulates in the abdominal region). This suggests that the mechanism for obesity-related foot pain may be metabolic as well as mechanical.

Depressive symptoms are associated with presence $[9,14]$ and severity $[15-17]$ of foot pain cross-sectionally. The association also holds in the reverse, with people with existing foot pain also having lower scores on health-related quality of life questionnaires cross-sectionally $[18,19]$. Poor mental health predicts worsening of foot pain longitudinally in community dwelling participants over 3 years [20].

\section{Page 3}

(C) 2018. This manuscript version is made available under the CC-BY-NC-ND 4.0 license http://creativecommons.org/licenses/by-nc-nd/4.0/ https://doi.org/10.1016/j.maturitas.2018.10.004 
Cross-sectionally, foot pain is associated with pain in multiple sites elsewhere: back, hips, knees $[17,18]$, hands and / or wrists [17]. Multi-site joint pain is important because having pain in some sites predicts incidence of new pain elsewhere [21], and because number of sites of pain is an effect modifier [22], leading to poorer quality of life both cross-sectionally [23] and longitudinally [23, 24], equivalent to a dose response for pain. No studies have examined the effect of multi-site joint pain on pain in new joints, whether some joints are more closely associated with foot pain than others, if the effects are additive, and whether these associations continue to hold longitudinally as well as cross-sectionally. We have previously reported that multi-site joint pain is also associated with fat mass and body mass [25]; however, it is unclear whether these factors are independent in the context of foot pain.

This study aimed to describe non-structural factors associated with foot pain both cross-sectionally and longitudinally over 5 years, in a community dwelling sample of older adults.

\section{Page 4}

(c) 2018. This manuscript version is made available under the CC-BY-NC-ND 4.0 license http://creativecommons.org/licenses/by-nc-nd/4.0/ https://doi.org/10.1016/j.maturitas.2018.10.004 


\section{Methods}

Study design, setting and participants

The Tasmanian Older Adult Cohort (TASOAC) study is a population-based cohort study, which aims to identify factors associated with the development and progression of osteoarthritis and osteoporosis in older adults. Men and women aged 50-80 years in 2002 were selected from the electoral roll in Southern Tasmania (population 229,000) using sex-stratified random sampling (response rate 57\%). Participants were excluded if they lived in an aged care facility, or had contraindications to magnetic resonance imaging. The Southern Tasmanian Health and Medical Human Research Ethics Committee approved the study, and we obtained written informed consent from all participants.

Baseline data (Phase 1) were collected from February 2002 to September 2004 in 1099 participants. Participants who did not have an MRI at Phase $1(n=105)$ were excluded from further participation in the study, as the primary aim of TASOAC was to measure progression of knee osteoarthritis. Follow up data (Phase 2 and 3) were collected on average 2.6 years (range $1.4-4.8$ ) and 5 years (range $3.6-6.9$ years) later, in 875 and 768 participants, respectively. Data in this paper were limited to participants with questionnaire data at Phase 1 (cross-sectional analyses) and Phase 3 (longitudinal analyses).

\section{Outcome: Foot pain}

Self-reported foot pain was assessed by questionnaire at Phases 1-3. Participants were asked "Do you have pain at any of these sites?". New foot pain was calculated

\section{Page 5}

(C) 2018. This manuscript version is made available under the CC-BY-NC-ND 4.0 license http://creativecommons.org/licenses/by-nc-nd/4.0/ https://doi.org/10.1016/j.maturitas.2018.10.004 


\section{AUTHOR ACCEPTED MANUSCRIPT}

as presence of pain at Phase 3 in study participants who did not report foot pain at Phase 1.

\section{Predictors and correlates}

Measures assessed by questionnaire

Participants were asked whether they had pain at 7 sites (neck, back, hands, shoulders, hips, knees, or feet; all yes / no options). The Assessment of Quality of Life (AQoL) questionnaire [26] was administered. It is a generic quality of life (QoL) instrument which is a valid measure of QoL [27] and is reliable in population-based settings (Cronbach's $\alpha=0.81$ ) [28]. We used the psychological wellbeing subscale, which has three items ("If I think about how I sleep", "thinking about how I generally feel (regarding anxiety and depression)", "How much pain or discomfort do I experience?") with four response levels (scored 0-3 for each item), with scores for this subscale ranging from 0-9. We also collected self-reported current cigarette smoking prevalence and diabetes status (yes / no).

\section{Anthropometry}

We calculated BMI [weight (in kilograms)/height (in meters) ${ }^{2}$ ] using weight measured to the nearest $0.1 \mathrm{~kg}$ (with shoes, socks, bulky clothing and headwear removed) using a single pair of calibrated electronic scales (Seca Delta Model 707), and height measured to the nearest $0.1 \mathrm{~cm}$ (with shoes and socks removed) using a stadiometer. Waist and hip circumferences were measured to the nearest $0.1 \mathrm{~cm}$ using a constant tension tape (Figure Finder tape measure) directly over the skin. The arithmetic mean of two measurements was used for analysis. Participants underwent a whole-body dual X-ray absorptiometry (DXA) scan using a Hologic

\section{Page 6}

(C) 2018. This manuscript version is made available under the CC-BY-NC-ND 4.0 license http://creativecommons.org/licenses/by-nc-nd/4.0/ https://doi.org/10.1016/j.maturitas.2018.10.004 
Delphi densitometer (Hologic, Waltham, MI), from which body composition was determined. We excluded participants from the DXA scans if their weight exceeded $130 \mathrm{~kg}(\mathrm{n}=3)$. The analysis provided mass in grams of total body fat and trunk fat.

\section{Serum lipids}

Study participants provided a blood sample, after a 12-hour overnight fast. This was used to assess total cholesterol, high-density lipoprotein (HDL) cholesterol, and triglycerides. These were assessed enzymatically using an Olympus AU5400 automated analyzer. The concentration of LDL cholesterol was calculated by using the Friedewald formula [29]. Assays were performed on thawed blood samples.

\section{Other measures}

Blood pressure was measured using an OMRON HEM907 digital automatic blood pressure monitor; the arithmetic mean of two measurements was used for analysis (less than $2 \mathrm{mmHg}$ apart). Presence of metabolic syndrome was calculated using the Alberti et al [30] criteria. Metabolic syndrome was defined as 3 or more of 5 risk factors: abdominal obesity (waist circumference (WC) using European criteria >102 $\mathrm{cm}$ in men; >88 cm in women), hypertriglyceridemia (triglycerides $(T G) \geq 1.7 \mathrm{mmol} / \mathrm{L}$ ), low level of high-density lipoprotein cholesterol (HDL-C) (i.e. HDL-C 1.0 mmol/L in men and $1.3 \mathrm{mmol} / \mathrm{L}$ in women), high blood pressure $(B P)(B P \geq 130 / 85 \mathrm{mmHg}$ ) and high levels of fasting plasma glucose (GL) (i.e. $G L \geq 110 \mathrm{mg} / \mathrm{dL}$ ( $\geq 5.5 \mathrm{mmol} / \mathrm{L}$ ) [30].

Leg strength was measured to the nearest kilogram in both legs simultaneously, using a dynamometer (TTM Muscular Meter, Tokyo, Japan) as previously described [31]. Physical activity (number of steps per day) was measured using a pedometer (Omron HJ-003 \& HJ-102, Omron Healthcare, Kyoto, Japan). Briefly,

\section{Page 7}

(c) 2018. This manuscript version is made available under the CC-BY-NC-ND 4.0 license http://creativecommons.org/licenses/by-nc-nd/4.0/ https://doi.org/10.1016/j.maturitas.2018.10.004 
number of steps per day was calculated as an average of seven consecutive days and averaged across two time points in different seasons [32].

\section{Statistical analysis}

Basic group comparisons were performed using Students' t-tests and chi square tests to examine differences in means and proportions, respectively. The two outcomes; baseline (prevalent) foot pain, and incident foot pain after five years, were modelled using log binomial regression [33]. All potential predictors were assessed adjusted for age and sex. Number of sites of pain were categorised for entry into the models.

We selected BMI for entry into the models in Table 2 and Table 4 as the units are standardised for both genders, however, associations with other anthropometry measures and foot pain were investigated further (Table 3). We applied inverse probability weighting (IPW) to adjust for potential bias due to non-random dropout of study participants in the longitudinal model. The IPW model was based on age, sex, smoking status, diagnosed diabetes, prevalence of neck pain and steps per day at baseline.

Statistical significance was defined as a p value $\leq 0.05$ (two tailed). We used Stata 15.0 (StataCorp LP) for all statistical analyses.

\section{Page 8}

(c) 2018. This manuscript version is made available under the CC-BY-NC-ND 4.0 license http://creativecommons.org/licenses/by-nc-nd/4.0/ https://doi.org/10.1016/j.maturitas.2018.10.004 


\section{Results}

Participants who reported foot pain at baseline (in 2002-2004, n=1092) were more likely to be female, have more obese anthropometry profiles (weight, BMI, waist circumference, waist-to-hip ratio), have diagnosed diabetes or metabolic syndrome, and have weaker leg strength. They walked fewer steps per day, reported pain in greater numbers of sites and reported worse quality of life (psychological wellbeing subscale). Participants with incident foot pain at 5 years $(2007-2009, n=476)$ were more likely to be female, have higher BMI and hip circumference, less leg strength, have pain at greater number of sites and have poorer psychological wellbeing (Table 1).

Approximately $30 \%$ of study participants were lost to follow up over 5 years of observation, with those lost to follow up older (65 vs 62 years), more likely to smoke cigarettes (18 vs 10\%), have been diagnosed with diabetes (9.2 vs $3.2 \%$ ), walk fewer steps per day (8100 vs 9100 ), and have neck pain (41 vs $35 \%$ ) than those retained in the study. Participants lost to follow up were not different in terms of BMI, weight, psychological wellbeing, number of painful sites, or pain in specific sites (excepting neck pain). Longitudinal analyses were inverse probability weighted for factors associated with loss to follow up.

Study participants with higher BMI were at increased risk of prevalent or incident foot pain (Table 2, Table 5). Figure 1 demonstrates that this association is linear crosssectionally, but is increased only in individuals with BMI $\geq 30$ longitudinally. Compared to those with no painful joints, participants with 3 or more painful joints

\section{Page 9}

(c) 2018. This manuscript version is made available under the CC-BY-NC-ND 4.0 license http://creativecommons.org/licenses/by-nc-nd/4.0/ https://doi.org/10.1016/j.maturitas.2018.10.004 
were at increased risk of prevalent or incident foot pain, although the latter did not reach statistical significance (Table 2).

We further investigated the effect of different methods of assessing fat mass on prevalent and incident foot pain, using standardised coefficients to enable comparability between different measures. All simple methods of assessment, and metabolic syndrome were associated with foot pain cross-sectionally (Table 3), but of the more complex, DXA-based measures, fat mass was associated with foot pain cross-sectionally, even after adjustment for height. Lean mass was associated with prevalent foot pain only when adjusted for height (Table 3). Incident foot pain was associated with all of the simple measures of fat mass longitudinally (weight, BMI, waist circumference, waist-to-hip ratio), with similar effect sizes longitudinally as observed in the cross-sectional analyses. Of the DXA-based measures of fat and lean mass, lean mass (g) was statistically significant longitudinally (after adjustment for fat mass, age and sex, but not when adjusted for height). No other DXA based fat mass measures were associated with incident foot pain. When we examined the individual components of the metabolic syndrome (Table 4), only elevated waist circumference was statistically significant both cross-sectionally and longitudinally.

Neither change in BMI nor change in weight predicted incident foot pain (Table 3). However, both weight and BMI were stable over 5 years in this population (Table 1). Study participants with poor psychological wellbeing were also at increased risk of foot pain at baseline; associations persisted over 5 years but did not reach statistical significance. Steps per day was not associated with prevalent or incident foot pain over 5 years (Table 2, Table 5). We also investigated associations between foot 
pain and specific joints. Associations were strongest at the neck, hands and knees; these were statistically significant both cross-sectionally and longitudinally (Table 2, Table 5).

We conducted a sensitivity analysis on the Psychological Wellbeing score, as one of the items asked about pain, and therefore associations could be due to similarity in questions. Omitting the question on pain and recalculating the scale with the remaining two items (sleep, how I generally feel) made minimal difference to associations (data not shown).

Self-reported diabetes, and current or ever smoking were not associated with prevalent or incident foot pain after adjustment for age, sex and BMI (data not shown).

Page 11

(C) 2018. This manuscript version is made available under the CC-BY-NC-ND 4.0 license http://creativecommons.org/licenses/by-nc-nd/4.0/ https://doi.org/10.1016/j.maturitas.2018.10.004 


\section{Discussion}

This prospective population-based study demonstrates that greater body mass and presence of joint pain at multiple sites are consistently associated with foot pain, both cross-sectionally and longitudinally, with every additional standard deviation of weight or BMI (approx. 15kg, or 4.75 unit increase in BMI) conferring a $20 \%$ increase in likelihood of prevalent foot pain and a $24 \%$ increase in risk of new foot pain over 5 years. Poor psychological wellbeing is also associated with foot pain crosssectionally, but did not remain statistically significant longitudinally even though effect sizes were similar. Diabetes and smoking were not associated with either prevalent or incident foot pain. Overall, reducing the burden of foot pain is in the community will require interventions aimed at multiple risk factors.

The method of assessment of body mass did not affect the magnitude of positive associations between obesity and foot pain either cross-sectionally or longitudinally. These data are consistent with results of a recent meta-analysis, which found that BMI is associated with non-specific foot pain cross-sectionally [8]; and are consistent with data suggesting that the body composition measure with the strongest association with foot pain cross-sectionally is fat mass [11]. However, our data are not completely consistent with previous findings suggesting that BMI was associated with incident foot "problems" (as compared to pain); Menz et al reported that neither BMI nor weight at baseline was associated with incident foot pain in women aged 70 years and over, although having an increase in $\mathrm{BMI}>12 \%$ (RR 1.14) was significantly associated with incident foot problems over a 6 year period [9]. We observed a $20 \%$ increased risk of baseline foot pain and a $24 \%$

Page 12

(c) 2018. This manuscript version is made available under the CC-BY-NC-ND 4.0 license http://creativecommons.org/licenses/by-nc-nd/4.0/ https://doi.org/10.1016/j.maturitas.2018.10.004 
increase of incident foot pain per standard deviation in weight. Differences in results between studies could be explained either by different populations or by different methods of comparison. With regard to the more complex measures of assessing obesity, using DXA, fat mass was associated with foot pain cross-sectionally but not longitudinally (after adjustment for lean mass, age and sex, and normalised for height). Lean mass was only associated with prevalent foot pain when normalised for height. Associations between fat mass and foot pain could be due either to the effects of mechanical loading or via inflammatory factors, which are elevated in people with greater fat mass. Our finding of an association with waist circumference supports a role for a metabolic effect, but it is unlikely to be driven by other components of metabolic syndrome (Table 4). Associations with lean mass and incident pain is novel and the reason behind this is unclear. In contrast to Menz et al [9], we did not find that change in weight or BMI were associated with incident foot pain after 5 years. However, the strength of this conclusion is tempered by the observation that these factors were stable over time in our population.

We found that pain at other sites was associated with foot pain. When expressed as number of affected sites, the threshold was three sites, but this was statistically significant only at baseline. When the location of pain was taken into account, pain in the neck, hands or knees was associated with increased risk of prevalent and incident foot pain. We found no such effect with pain in other regions assessed (shoulders, back, hips), but the reason for this remains unclear. This is broadly consistent with existing literature $[17,18]$, although the specific sites associated with foot pain differed across studies. The association with knee pain could be explained biomechanically (i.e. knee pain may result in altered walking patterns which place

(c) 2018. This manuscript version is made available under the CC-BY-NC-ND 4.0 license http://creativecommons.org/licenses/by-nc-nd/4.0/ https://doi.org/10.1016/j.maturitas.2018.10.004 
excessive loads on the foot), but the association with neck and hand pain requires an alternative explanation. Possibilities include a form of generalised osteoarthritis [34], or other systemic factors eg inflammatory cytokines.

Our data demonstrates associations between poor psychological wellbeing and existing foot pain, consistent with existing literature $[9,14,18,19]$. Prevalence of foot pain was higher in this population than in other studies of comparable ages and populations [1]. This might be due to different definitions and time horizons. We simply asked whether pain was present; the more widely used definitions (Framingham study, Manchester Foot Pain and Disability Index) require pain to be present on most days. Prevalence and incidence of foot pain was higher in males in this population, which is contrary to previous reports [1]. However, sex was not a correlate of foot pain at baseline or a predictor of new pain; therefore any differences in prevalence between sexes is unlikely to affect the applicability of study findings to the general population.

Strengths of this study include the random population based sampling, comprehensive data collection, and five-year period of observation, providing excellent external validity for our findings. The initial response rate is similar to comparable Australian studies (57\%) [18]. Loss to follow up ( $30 \%)$ was nonrandom, as expected, but data have been adjusted for factors associated with follow up and the resulting observations are largely consistent with cross-sectional associations.

Limitations include lack of clinical examination or imaging data on feet, which limits our ability to assess structural correlates and predictors of foot pain; and absence of

(c) 2018. This manuscript version is made available under the CC-BY-NC-ND 4.0 license http://creativecommons.org/licenses/by-nc-nd/4.0/ https://doi.org/10.1016/j.maturitas.2018.10.004 
information on psychological factors, such as diagnosed mental health conditions or psychological distress: this limits our ability to consider such conditions as covariates or effect modifiers. Also, our assessment of joint pain asks about a joint type ("knees") but with the exception of the knees, collection of data on pain as binary (yes / no) precludes investigations of associations with pain severity or differentiation between 1 and 2 sore joints within these joint classes. The latter is likely to increase measurement error, which would reduce strength of associations rather than increase it.

Obesity is a modifiable risk factor, with evidence demonstrating that foot pain reduces following weight loss surgery [35], and weight loss results in a reduction in foot loading when walking [36]. However, change in BMI or weight were not associated with incident foot pain in our cohort, but weight was stable in this population (average change $0.43 \pm 4.5 \mathrm{~kg}$ over 5 years) which may have limited our ability to detect a difference. This data suggests a role for body mass as a driver of foot pain, with this association not being driven primarily by abdominal obesity.

\section{Conclusions}

Obesity and pain at other sites are consistently associated with prevalent foot pain and predict incident foot pain. This suggests that reducing obesity in the community may reduce the prevalence of foot pain, and that taking a global approach to the treatment of pain may reduce both prevalence and incidence of foot pain in older adults.

\section{Page 15}

(c) 2018. This manuscript version is made available under the CC-BY-NC-ND 4.0 license http://creativecommons.org/licenses/by-nc-nd/4.0/ https://doi.org/10.1016/j.maturitas.2018.10.004 


\section{Acknowledgements}

We especially thank the participants who made this study possible, and we gratefully acknowledge the role of the Tasmanian Older Adult Cohort (TASOAC) staff and volunteers in collecting the data, particularly research nurses Catrina Boon and Pip Boon. We thank Professor C. Leigh Blizzard for providing the user-written syntax for the log binomial modelling.

\section{Contributors}

GJ designed and obtained funding for the original TASOAC study.

Analyses were designed by LLL, HBM and GJ, and conducted by LLL with advice from PO. LLL, HBM, FP, FC and GJ contributed to data interpretation. All authors drafted the article and critically revised it for important intellectual content, and approved the final version of the article.

\section{Conflict of interest}

None of the authors have any conflicts of interest to declare for the work under consideration for publication. 


\section{Reference List}

[1] M.J. Thomas, E. Roddy, W. Zhang, H.B. Menz, M.T. Hannan, G.M. Peat, The population prevalence of foot and ankle pain in middle and old age: a systematic review, Pain 152 (2011) 2870-80.

[2] G. Peat, E. Thomas, R. Wilkie, P. Croft, Multiple joint pain and lower extremity disability in middle and old age, Disabil Rehabil 28 (2006) 1543-9.

[3] H.B. Menz, M.E. Morris, S.R. Lord, Foot and ankle characteristics associated with impaired balance and functional ability in older people, J Gerontol A Biol Sci Med Sci 60 (2005) 1546-52.

[4] H.B. Menz, M.E. Morris, S.R. Lord, Foot and ankle risk factors for falls in older people: a prospective study, J Gerontol A Biol Sci Med Sci 61 (2006) 866-70.

[5] A. Bowling, E. Grundy, Activities of daily living: changes in functional ability in three samples of elderly and very elderly people, Age Ageing 26 (1997) 10714.

[6] J.J. Keysor, J.E. Dunn, C.L. Link, F. Badlissi, D.T. Felson, Are foot disorders associated with functional limitation and disability among community-dwelling older adults?, J Aging Health 17 (2005) 734-52.

[7] K.L. Paterson, J. Kasza, D.J. Hunter, R.S. Hinman, H.B. Menz, G. Peat, K.L. Bennell, The relationship between foot and ankle symptoms and risk of developing knee osteoarthritis: data from the osteoarthritis initiative, Osteoarthritis Cartilage 25 (2017) 639-646.

[8] P.A. Butterworth, K.B. Landorf, S.E. Smith, H.B. Menz, The association between body mass index and musculoskeletal foot disorders: a systematic review, Obes Rev 13 (2012) 630-42.

[9] H.B. Menz, E.L. Barr, W.J. Brown, Predictors and persistence of foot problems in women aged 70 years and over: a prospective study, Maturitas 68 (2011) 83-7.

[10] A. Gay, D. Culliford, K. Leyland, N.K. Arden, C.J. Bowen, Associations between body mass index and foot joint pain in middle-aged and older women: a longitudinal population-based cohort study, Arthritis Care Res (Hoboken) 66 (2014) 1873-9.

[11] S.K. Tanamas, A.E. Wluka, P. Berry, H.B. Menz, B.J. Strauss, M. DaviesTuck, J. Proietto, J.B. Dixon, G. Jones, F.M. Cicuttini, Relationship between obesity and foot pain and its association with fat mass, fat distribution, and muscle mass, Arthritis Care Res (Hoboken) 64 (2012) 262-8.

[12] T.P. Walsh, T.K. Gill, A.M. Evans, A. Yaxley, E.M. Shanahan, C.L. Hill, Association of fat mass and adipokines with foot pain in a community cohort, Arthritis Care Res (Hoboken) 68 (2016) 526-33.

[13] P.A. Butterworth, D.M. Urquhart, F.M. Cicuttini, H.B. Menz, B.J. Strauss, J. Proietto, J.B. Dixon, G. Jones, K.B. Landorf, A.E. Wluka, Fat mass is a predictor of incident foot pain, Obesity (Silver Spring) 21 (2013) E495-9.

[14] Y.M. Golightly, M.T. Hannan, X.A. Shi, C.G. Helmick, J.B. Renner, J.M. Jordan, Association of foot symptoms with self-reported and performancebased measures of physical function: The Johnston County osteoarthritis project, Arthritis Care Res (Hoboken) 63 (2011) 654-9.

[15] A. Awale, A.B. Dufour, P. Katz, H.B. Menz, M.T. Hannan, Link Between Foot Pain Severity and Prevalence of Depressive Symptoms, Arthritis Care Res (Hoboken) 68 (2016) 871-6. 
[16] M.P. Cotchett, G. Whittaker, B. Erbas, Psychological variables associated with foot function and foot pain in patients with plantar heel pain, Clin Rheumatol 34 (2015) 957-64.

[17] H.B. Menz, A. Tiedemann, M.M. Kwan, K. Plumb, S.R. Lord, Foot pain in community-dwelling older people: an evaluation of the Manchester Foot Pain and Disability Index, Rheumatology (Oxford) 45 (2006) 863-7.

[18] C.L. Hill, T.K. Gill, H.B. Menz, A.W. Taylor, Prevalence and correlates of foot pain in a population-based study: the North West Adelaide health study, J Foot Ankle Res 1 (2008) 2.

[19] K.J. Mickle, B.J. Munro, S.R. Lord, H.B. Menz, J.R. Steele, Cross-sectional analysis of foot function, functional ability, and health-related quality of life in older people with disabling foot pain, Arthritis Care Res (Hoboken) 63 (2011) 1592-8.

[20] P.A. Butterworth, D.M. Urquhart, F.M. Cicuttini, H.B. Menz, B.J. Strauss, J. Proietto, J.B. Dixon, G. Jones, A.E. Wluka, Relationship between mental health and foot pain, Arthritis Care Res (Hoboken) 66 (2014) 1241-5.

[21] L.L. Laslett, P. Otahal, E.M. Hensor, S.R. Kingsbury, P.G. Conaghan, Knee Pain Predicts Subsequent Shoulder Pain and the Association Is Mediated by Leg Weakness: Longitudinal Observational Data from the Osteoarthritis Initiative, J Rheumatol 43 (2016) 2049-2055.

[22] P. Suri, D.C. Morgenroth, C.K. Kwoh, J.F. Bean, L. Kalichman, D.J. Hunter, Low back pain and other musculoskeletal pain comorbidities in individuals with symptomatic osteoarthritis of the knee: data from the osteoarthritis initiative, Arthritis Care Res 62 (2010) 1715-23.

[23] L.L. Laslett, S.J. Quinn, T.M. Winzenberg, K. Sanderson, F. Cicuttini, G. Jones, A prospective study of the impact of musculoskeletal pain and radiographic osteoarthritis on health related quality of life in community dwelling older people, BMC Musculoskelet Disord 13 (2012) 168.

[24] T.J. Hoogeboom, A.A. den Broeder, R.A. de Bie, C.H. van den Ende, Longitudinal impact of joint pain comorbidity on quality of life and activity levels in knee osteoarthritis: data from the Osteoarthritis Initiative, Rheumatology (Oxford) 52 (2013) 543-6.

[25] F. Pan, L. Laslett, L. Blizzard, F. Cicuttini, T. Winzenberg, C. Ding, G. Jones, Associations Between fat mass and multisite pain: a five-year longitudinal study, Arthritis Care Res (Hoboken) 69 (2017) 509-516.

[26] G. Hawthorne, J. Richardson, N. Day, H. McNeil, Using the 'Assessment of Quality of Life' (AQoL) Instrument, Centre for Health Program Evaluation, Melbourne, 2000.

[27] R.H. Osborne, G. Hawthorne, E.A. Lew, L.C. Gray, Quality of life assessment in the community-dwelling elderly: validation of the Assessment of Quality of Life (AQoL) Instrument and comparison with the SF-36, J Clin Epidemiol 56 (2003) 138-47.

[28] G. Hawthorne, R. Osborne, Population norms and meaningful differences for the Assessment of Quality of Life (AQoL) measure, Aust N Z J Public Health 29 (2005) 136-42.

[29] W.T. Friedewald, R.I. Levy, D.S. Fredrickson, Estimation of the concentration of low-density lipoprotein cholesterol in plasma, without use of the preparative ultracentrifuge, Clin Chem 18 (1972) 499-502.

[30] K.G. Alberti, R.H. Eckel, S.M. Grundy, P.Z. Zimmet, J.I. Cleeman, K.A. Donato, J.C. Fruchart, W.P. James, C.M. Loria, S.C. Smith, Jr., E. 
International Diabetes Federation Task Force on, Prevention, L. Hational Heart, I. Blood, A. American Heart, F. World Heart, S. International Atherosclerosis, O. International Association for the Study of, Harmonizing the metabolic syndrome: a joint interim statement of the International Diabetes Federation Task Force on Epidemiology and Prevention; National Heart, Lung, and Blood Institute; American Heart Association; World Heart Federation; International Atherosclerosis Society; and International Association for the Study of Obesity, Circulation 120 (2009) 1640-5.

[31] D. Scott, L. Blizzard, J. Fell, G. Jones, Statin therapy, muscle function and falls risk in community-dwelling older adults, QJM 102 (2009) 625-33.

[32] D. Scott, L. Blizzard, J. Fell, G. Jones, Ambulatory activity, body composition, and lower-limb muscle strength in older adults, Med Sci Sports Exerc 41 (2009) 383-9.

[33] M.R. Petersen, J.A. Deddens, Maximum Likelihood Estimation of the LogBinomial Model, Communications in Statistics - Theory and Methods 39 (2010) 874-883.

[34] A.E. Nelson, M.W. Smith, Y.M. Golightly, J.M. Jordan, "Generalized osteoarthritis": a systematic review, Semin Arthritis Rheum 43 (2014) 713-20.

[35] M.M. Hooper, T.A. Stellato, P.T. Hallowell, B.A. Seitz, R.W. Moskowitz, Musculoskeletal findings in obese subjects before and after weight loss following bariatric surgery, Int J Obes (Lond) 31 (2007) 114-20.

[36] J. Song, R. Kane, D.N. Tango, S.S. Veur, J. Furmato, E. Komaroff, G.D. Foster, Effects of weight loss on foot structure and function in obese adults: a pilot randomized controlled trial, Gait Posture 41 (2015) 86-92. 
Table 1: Characteristics of the study population at baseline, by presence of foot pain

\begin{tabular}{|c|c|c|c|c|c|c|}
\hline \multirow[t]{2}{*}{ Baseline characteristics } & \multicolumn{3}{|c|}{$\begin{array}{l}\text { All study participants at baseline } \\
\text { (Phase 1) }(n=1092)\end{array}$} & \multicolumn{3}{|c|}{$\begin{array}{l}\text { Participants who completed } 5 \text { year follow up } \\
\text { and did not have foot pain at baseline } \\
\qquad(n=494)\end{array}$} \\
\hline & $\begin{array}{l}\text { No foot pain } \\
n=680\end{array}$ & $\begin{array}{l}\text { Foot pain } \\
n=412\end{array}$ & $\mathrm{p}$ & $\begin{array}{c}\text { No new foot pain } \\
n=397\end{array}$ & $\begin{array}{c}\text { New foot pain } \\
n=97\end{array}$ & $p$ \\
\hline Age (years) & $63.0(7.4)$ & $63.1(7.6)$ & 0.73 & $62.2(7)$ & $61.6(7.2)$ & 0.49 \\
\hline Sex (\% male) & 51 & 45 & 0.037 & 54 & 41 & 0.02 \\
\hline Current smokers (\%) & 12 & 11 & 0.65 & 11 & 7 & 0.32 \\
\hline Diagnosed diabetes (\%) (self-reported) & 5.1 & 8.3 & 0.04 & 3.5 & 4.1 & 0.78 \\
\hline Weight $(\mathrm{kg})$ & $76.5(14.6)$ & $80.2(15.4)$ & 0.0001 & $76.5(13.9)$ & $78.0(15.8)$ & 0.33 \\
\hline Body mass index (BMI) & $27.3(4.4)$ & $28.9(5.2)$ & $<0.001$ & $27.1(4.1)$ & $28.1(4.8)$ & 0.03 \\
\hline Waist circumference $(\mathrm{cm})$ & $92.5(12.7)$ & $96.7(13.5)$ & $<0.001$ & $92.0(12.3)$ & $92.7(12.6)$ & 0.60 \\
\hline Hip circumference $(\mathrm{cm})$ & $100.7(8.4)$ & $103.9(9.3)$ & $<0.001$ & $100.4(8.1)$ & $102.3(8.7)$ & 0.037 \\
\hline Waist-hip ratio (waist/hip) & $0.9(0.1)$ & $0.9(0.1)$ & 0.04 & $0.9(0.1)$ & $0.9(0.1)$ & 0.29 \\
\hline Metabolic syndrome (\%) & 31 & 44 & 0.0001 & 30 & 32 & 0.78 \\
\hline Total fat mass $(\mathrm{kg})$ & $27.0(8.3)$ & $30.5(9.1)$ & $<0.001$ & $26.5(8.0)$ & $28.0(9)$ & 0.056 \\
\hline Total lean mass $(\mathrm{kg})$ & $52.1(10.6)$ & $52.1(10.3)$ & 0.90 & $52.6(10.2)$ & $52(11.8)$ & 0.58 \\
\hline Leg strength $(\mathrm{kg})$ & $97.1(48.5)$ & $84.3(48.9)$ & $<0.001$ & $100.5(48)$ & $90.6(50.5)$ & 0.07 \\
\hline Pedometer steps per day & $9749(3686)$ & $8968(3637)$ & $<0.001$ & 9979 (3566) & $10268(4257)$ & 0.81 \\
\hline \multicolumn{7}{|l|}{ Proportion (\%) with pain in the: } \\
\hline Neck & 36 & 64 & $<0.001$ & 31 & 48 & 0.50 \\
\hline Shoulder & 36 & 58 & $<0.001$ & 33 & 43 & 0.26 \\
\hline Back & 53 & 76 & $<0.001$ & 51 & 58 & $<0.001$ \\
\hline Hands & 32 & 64 & $<0.001$ & 28 & 45 & 0.12 \\
\hline Hips & 33 & 56 & $<0.001$ & 31 & 39 & $<0.001$ \\
\hline Knees & 34 & 67 & $<0.001$ & 30 & 44 & $<0.001$ \\
\hline Number of sites of pain & 2.2 & 3.8 & $<0.001$ & 2.0 & 2.8 & $<0.001$ \\
\hline Quality of life - Psychological Wellbeing & $2(1.5)$ & $3(1.6)$ & $<0.001$ & 1.8 & 2.2 & 0.02 \\
\hline
\end{tabular}

mean \pm standard deviation (SD). $P$ values calculated using t-tests.

Body mass index $(\mathrm{BMI})=\left(\right.$ weight $(\mathrm{kg}) /$ height $\left.(\mathrm{m})^{2}\right)$ 
Table 2: Factors associated with foot pain at baseline and incident pain after 5 years: Number of painful joints

\begin{tabular}{|c|c|c|}
\hline & $\begin{array}{l}\text { Associations with foot pain at } \\
\text { baseline } \\
\text { Prevalence ratio }(95 \% \mathrm{Cl}) \\
\mathrm{n}=1042\end{array}$ & $\begin{array}{l}\text { Associations with incident } \\
\text { foot pain after } 5 \text { years } \\
\text { Risk ratio }(95 \% \mathrm{Cl}) \\
\mathrm{n}=477^{\dagger}\end{array}$ \\
\hline BMI & $1.01(1.01$ to 1.02$)$ & 1.05 (1.01 to 1.09$)$ \\
\hline \multicolumn{3}{|l|}{ Number of painful joints } \\
\hline 0 & Reference & Reference \\
\hline $1-2$ & $1.23(0.82$ to 1.86$)$ & $1.23(0.66$ to 2.30$)$ \\
\hline $3-6$ & $2.33(1.6$ to 3.4$)$ & $1.80(0.98$ to 3.30$)$ \\
\hline \multicolumn{3}{|l|}{ Psychological Wellbeing } \\
\hline subscale of the AQoL & $1.16(1.11$ to 1.21$)$ & 1.07 (0.95 to 1.21$)$ \\
\hline Steps per day & 0.99 (0.96 to 1.01$)$ & 1.05 (0.99 to 1.12$)$ \\
\hline
\end{tabular}

Adjusted for age and sex, associations estimated using log-binomial regression

${ }^{\S}$ For each 1000 steps

†Actual number of participants, analyses were inverse probability weighted for factors associated with loss to follow up

Table 3: Associations between different measures of body fat and foot pain at baseline and incident pain after 5 years

\begin{tabular}{|c|c|c|}
\hline & $\begin{array}{l}\text { Associations with foot } \\
\text { pain at baseline }\end{array}$ & $\begin{array}{l}\text { Associations with incident } \\
\text { foot pain after } 5 \text { years }\end{array}$ \\
\hline & $\begin{array}{l}\text { RR per SD }(95 \% \mathrm{Cl}) \\
\mathrm{n}=1092\end{array}$ & $\begin{array}{l}\text { RR per SD }(95 \% \mathrm{Cl}) \\
\mathrm{n}=476 \dagger\end{array}$ \\
\hline Weight & 1.20 (1.13 to 1.28$)$ & 1.24 (1.03 to 1.49$)$ \\
\hline Body mass index (BMI) & 1.19 (1.13 to 1.25$)$ & 1.24 (1.04 to 1.49$)$ \\
\hline Waist circumference & 1.26 (1.19 to 1.34$)$ & $1.22(1.01$ to 1.49$)$ \\
\hline Hip circumference & 1.19 (1.13 to 1.25$)$ & 1.18 (0.99 to 1.40$)$ \\
\hline Waist-to-hip ratio & 1.27 (1.16 to 1.39$)$ & 1.23 (0.95 to 1.61$)$ \\
\hline Metabolic syndrome & $1.21(1.12$ to 1.30$)$ & 1.25 (0.85 to 1.83$)$ \\
\hline Total fat mass $(\mathrm{kg})^{*}$ & $1.28(1.18$ to 1.40$)$ & $0.92(0.71$ to 1.19$)$ \\
\hline Fat mass index & 1.21 (1.18 to 1.24$)$ & 1.16 (0.93 to 1.46$)$ \\
\hline Total lean mass $(\mathrm{kg})^{\S}$ & $0.92(0.78$ to 1.08$)$ & 1.61 (1.07 to 2.43$)$ \\
\hline Lean mass index & 1.19 (1.05 to 1.34$)$ & 1.41 (1.11 to 1.79$)$ \\
\hline Change in $\mathrm{BMI}$ & - & 1.11 (0.93 to 1.34$)$ \\
\hline Change in weight & & 1.13 (0.93 to 1.36$)$ \\
\hline
\end{tabular}

Standardised coefficients used (RR per standard deviation) (excepting metabolic syndrome).

All measures were at baseline except change in BMI and change in weight.

Adjusted for age and sex, associations estimated using log binomial regression

BMI: body mass index (weight / height ${ }^{2}$ )

Fat mass index: (fat mass / height ${ }^{2}$ )

Lean mass index:(lean mass / height ${ }^{2}$ )

${ }^{¥}$ Additionally adjusted for lean mass $(\mathrm{kg})$

${ }^{\S}$ Additionally adjusted for fat mass $(\mathrm{kg})$

†Actual number of participants, analyses were inverse probability weighted for factors associated with loss to follow up 
Table 4: Associations between components of metabolic syndrome and foot pain

\begin{tabular}{|c|c|c|}
\hline & $\begin{array}{l}\text { Associations with foot } \\
\text { pain at baseline } \\
\text { Prevalence ratio }(95 \% \mathrm{Cl}) \\
n=1079\end{array}$ & $\begin{array}{l}\text { Associations with incident } \\
\text { foot pain after } 5 \text { years } \\
\text { Risk Ratio }(95 \% \mathrm{Cl}) \\
\mathrm{n}=473^{\dagger}\end{array}$ \\
\hline High waist circumference & $1.49(1.26$ to 1.75$)$ & $1.58(1.08$ to 2.32$)$ \\
\hline Low HDL & 1.11 (0.9 to 1.36$)$ & 0.87 (0.5 to 1.52$)$ \\
\hline High blood pressure & 0.95 (0.8 to 1.13$)$ & $0.96(0.64$ to 1.44$)$ \\
\hline High glucose & 0.94 (0.79 to 1.12$)$ & 1.25 (0.82 to 1.89$)$ \\
\hline High triglycerides & $1.18(1.00$ to 1.39$)$ & $0.74(0.46$ to 1.18$)$ \\
\hline
\end{tabular}

All measures were at baseline.

Adjusted for age and sex using log binomial regression

${ }^{\dagger}$ Actual number of participants, analyses were inverse probability weighted for factors associated with loss to follow up

Table 5: Factors associated with foot pain at baseline and incident foot pain after 5 years: site of painful joint

\begin{tabular}{|c|c|c|}
\hline & $\begin{array}{l}\text { Associations with foot } \\
\text { pain at baseline } \\
\text { Prevalence ratio }(95 \% \mathrm{Cl}) \\
\mathrm{n}=1036\end{array}$ & $\begin{array}{l}\text { Associations with incident } \\
\text { foot pain after } 5 \text { years } \\
\text { Risk ratio }(95 \% \mathrm{Cl}) \\
\mathrm{n}=477^{\dagger}\end{array}$ \\
\hline BMI & 1.01 (1.00 to 1.01$)$ & 1.05 (1.01 to 1.09$)$ \\
\hline \multicolumn{3}{|l|}{ Painful joint } \\
\hline None & Reference & Reference \\
\hline Neck & 1.33 (1.1 to 1.61$)$ & 1.59 (1.03 to 2.44$)$ \\
\hline Shoulder & 0.97 (0.84 to 1.13$)$ & 0.94 (0.61 to 1.45$)$ \\
\hline Back & 1.17 (0.94 to 1.45$)$ & 0.81 (0.54 to 1.21$)$ \\
\hline Hand & $1.52(1.28$ to 1.81$)$ & 1.58 (1.09 to 2.29$)$ \\
\hline Hips & $1.06(0.91$ to 1.24$)$ & 0.84 (0.57 to 1.24$)$ \\
\hline Knees & 1.67 (1.39 to 2.01$)$ & 1.47 (1.01 to 2.14$)$ \\
\hline \multicolumn{3}{|l|}{ Psychological Wellbeing } \\
\hline subscale of the AQoL & 1.07 (1.04 to 1.09$)$ & 1.08 (0.96 to 1.21$)$ \\
\hline Steps per day ${ }^{\S}$ & 0.99 (0.97 to 1.01$)$ & $1.06(0.998$ to 1.13$)$ \\
\hline
\end{tabular}

Adjusted for age and sex, estimates calculated using log binomial regression.

${ }^{\text {s}}$ For each 1000 steps

${ }^{\dagger}$ Actual number of participants, analyses were inverse probability weighted for factors associated with loss to follow up 


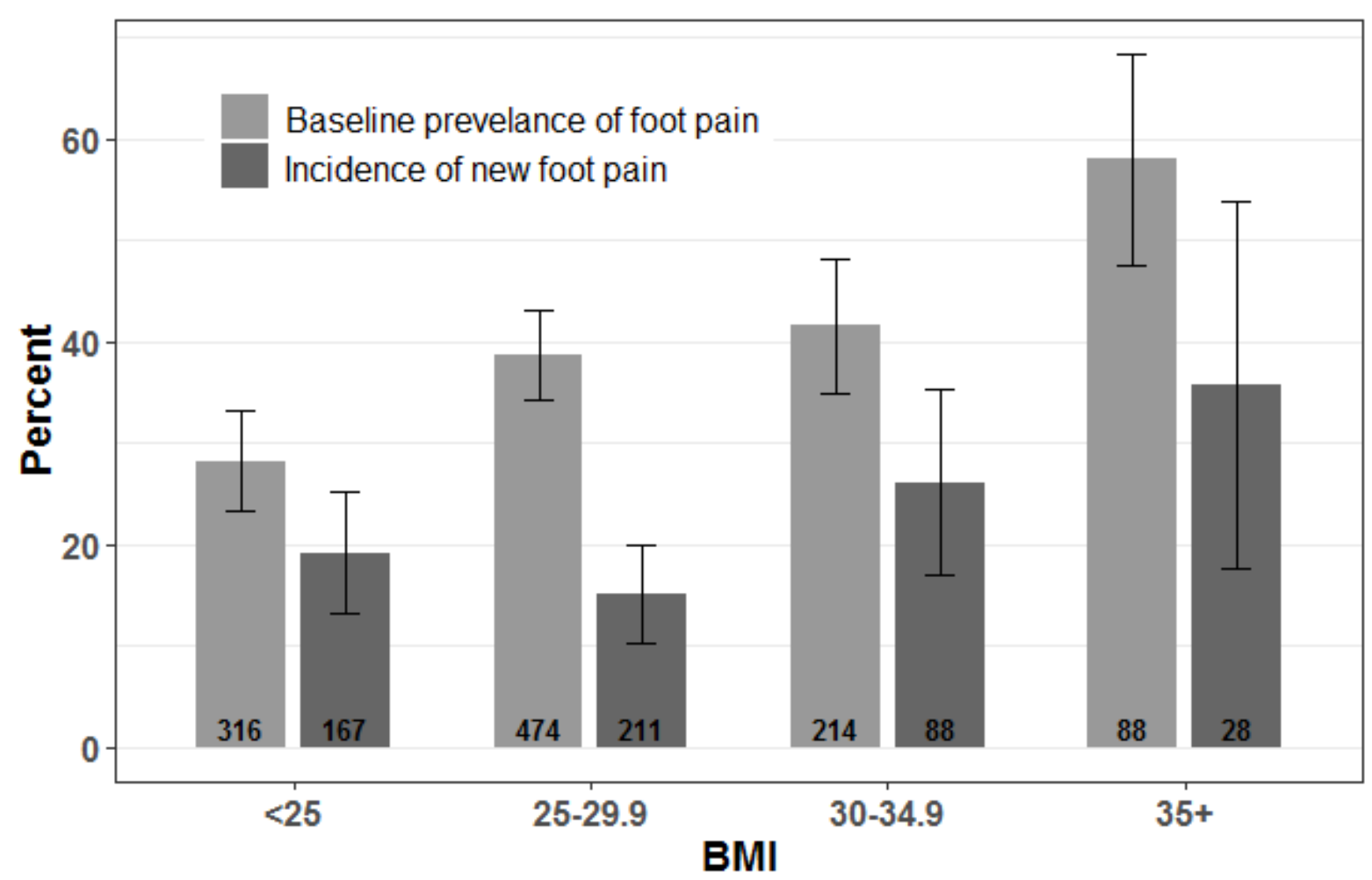

Figure 1: Prevalence of foot pain at baseline, and incident foot pain over 5 years, by categories of body mass index (unadjusted data) 


\section{AUTHOR ACCEPTED MANUSCRIPT}

\section{Table and figure legends}

Table 1: Characteristics of the study population at baseline, by presence of foot pain

Table 2: Factors associated with foot pain at baseline and incident pain after 5 years

Table 3: Associations between different measures of body fat and foot pain at baseline and incident pain after 5 years

Table 4: Unpacking metabolic syndrome: associations with components of metabolic syndrome and foot pain

Table 5: Baseline factors associated with foot pain at baseline and incident foot pain after 5 years

Figure 1: Prevalence of foot pain at baseline, and incident foot pain over 5 years, by categories of body mass index (unadjusted data) 